\title{
Bioinformatic screening and identification of downregulated hub genes in adrenocortical carcinoma
}

\author{
FANGSHI XU ${ }^{1,2}$, PENG ZHANG ${ }^{1}$, MIAO YUAN ${ }^{2}$ XIAOJIE YANG ${ }^{1}$ and TIE CHONG ${ }^{1}$ \\ ${ }^{1}$ Department of Urology, The Second Affiliated Hospital of Xi'an Jiaotong University, Xi'an, Shaanxi 710000; \\ ${ }^{2}$ Department of Medicine, Xi'an Jiaotong University, Xi'an, Shaanxi 710061, P.R. China
}

Received August 8, 2019; Accepted April 17, 2020

DOI: $10.3892 /$ etm.2020.8987

\begin{abstract}
The molecular mechanisms of adrenocortical carcinoma (ACC) carcinogenesis and progression remain unclear. In the present study, three microarray datasets from the Gene Expression Omnibus database were screened, which identified a total of 96 differentially expressed genes (DEGs). A protein-protein interaction network (PPI) was established for these DEGs and module analysis was performed using STRING and Cytoscape. A total of eight hub genes were identified from the most significant module; namely, calponin 1 (CNN1), myosin light chain kinase (MYLK), cysteine and glycine rich protein 1 (CSRP1), myosin heavy chain 11 (MYH11), fibulin extracellular matrix protein 2 (EFEMP2), fibulin 1 (FBLN1), microfibril associated protein 4 (MFAP4) and fibulin 5 (FBLN5). The biological functions of these hub genes were analyzed using the DAVID online tool. Changes in the expression of hub genes did not affect overall survival; however, downregulated EFEMP2 decreased disease-free survival. CSRP1 and MFAP4 expression levels were associated with adverse clinicopathological features. In conclusion, although all eight hub genes were downregulated in ACC, they appeared to have important functions in ACC carcinogenesis and progression. Identification of these genes complements the genetic expression profile of ACC and provides insight for the diagnosis, treatment and prognosis of ACC.
\end{abstract}

Correspondence to: Professor Tie Chong, Department of Urology, The Second Affiliated Hospital of Xi'an Jiaotong University, 157 West Five Road, Xi'an, Shaanxi 710000, P.R. China

E-mail: chongtie@126.com

Abbreviations: ACC, adrenocortical carcinoma; DEG, differentially expressed gene; PPI, protein-protein interaction; GO, Gene Ontology; MF, molecular function; BP biological process; $\mathrm{CC}$, cellular component

Key words: ACC, DEG, downregulated gene, enrichment analysis, PPI network, hub gene, survival analysis

\section{Introduction}

Adrenocortical carcinoma (ACC) is a rare urological tumor with an annual incidence of $0.7-2 /$ million (1). ACC is highly invasive and metastatic. Meanwhile, the prognosis of ACC is poor and most patients survive only 4-30 months. The 5-year overall survival rate is $16-47 \%$ and only $5-10 \%$ for advanced patients (2). In addition, diagnosis of ACC is difficult. Indeed, more than one-half of the patients display metastatic symptoms as the first clinical manifestation and many cases remain difficult to diagnose even after pathological diagnosis. Therefore, there is great interest in determining the molecular mechanisms of ACC onset and progression and in developing diagnostic and therapeutic strategies.

Microarray technologies and bioinformatics analysis have made high-throughput genome-wide sequencing and measurement of gene expression possible. Thus, key signaling pathways can be elucidated comprehensively and systematically, thereby revealing the molecular mechanisms of disease development and progression. In the present study, three mRNA microarray datasets from the Gene Expression Omnibus (GEO) database were screened for obtaining differentially expressed genes (DEGs) and ACC hub genes were chosen from the most significant module. Subsequently, a protein-protein interaction (PPI) network was established and gene enrichment, survival, co-expression and cluster analysis were performed for the hub genes. These analyses may help clarify the mechanisms of carcinogenesis and progression of ACC and identify new targets for treatment.

\section{Materials and methods}

Research process. In the present study, three microarray datasets from the GEO database (www.ncbi.nlm.nih.gov/geo/) were screened according to specific inclusion and exclusion criteria. A total of 96 DEGs were chosen to analyze. The PPI network of DEGs was constructed and corresponding enrichment analysis was performed. From these analyses, hub genes were identified from the most significant module (degree cutoff $=2$; node score cutoff $=0.2$; K-core $=2$ ) in the PPI network. Subsequently, enrichment, survival and cluster analysis were performed on these hub genes. Finally, the Oncomine online database (www.oncomine.org/) was used to further verify the differential expression of hub genes between ACC and normal 
tissue, and to analyze the relationships between clinical phenotypes and gene expression. Fig. 1 summarizes this research process.

Dataset screening. Relevant datasets were obtained from the GEO database using the key words 'Adrenal cortical carcinoma' OR 'Adrenocortical carcinoma' OR 'Adrenal carcinoma'. The research type was set to 'Expression profiling by array' and the organism was selected as 'Homo sapiens'. In total, 28 relevant datasets were initially identified. Datasets GSE19750 (3), GSE12368 (4) and GSE14922 (5) were ultimately selected according to the following inclusion criteria: i) Achievable comparison of ACC with normal adrenal tissue; and ii) original data can be downloaded in CEL format. In addition, the following exclusion criteria were applied: i) Childhood ACC; and ii) use of molecular targeted drugs for ACC before surgical treatment.

DEG identification. Using GEO 2R online analysis software (www.ncbi.nlm.nih.gov/geo/geo2r/), each dataset was divided into ACC group and normal tissue group. The TOP250 option was then used to obtain a genomic profile of DEGs between the tumor and normal groups in each dataset. A P-value $<0.01$ and $\operatorname{LogFC}$ absolute value $\geq 0.5$ were used as initial screening conditions, where FC indicates fold change. DEGs which are shared between datasets are presented in Venn diagrams.

KEGG and GO enrichment analyses. DEGs were subjected to gene enrichment analysis to obtain the main biological functions and signaling pathways in which they were involved. The Gene Ontology (GO) Consortium (geneontology.org/) is a database of new semantics vocabulary standards that are applicable to various species that can define and describe gene and protein functions (6). GO genetic annotations fall into three broad categories: i) Molecular function (MF); ii) biological process (BP); and iii) cellular component (CC). Gene function was defined and described according to these categories.

Kyoto Encyclopedia of Genes and Genomes (www.kegg. jp; version 94.0; KEGG) is a comprehensive database that integrates information on genomic, chemical and system functions (7). Using the KEGG database, information on the signaling pathways of genes can be obtained to deeply excavate the molecular mechanisms of the genes.

Database for Annotation, Visualization and Integrated Discovery (DAVID) is an online bioinformatics analysis and integration tool (david.ncifcrf.gov) for Functional Annotation, Gene Functional Classification, Gene ID Conversion and other analyses (8). DAVID (version 6.8) was used to complete the GO and KEGG enrichment analyses of DEGs and hub genes to obtain information on their molecular functions, biological processes, cytogenetics and signaling pathways.

PPI network construction and module analysis. Functional links among proteins often reflect the genetic association among their genes. A PPI network can be used to describe the interactions among proteins and identify hub regulatory genes of disease. The STRING database (version 11.0; string-db.org) can search for interactions between known and predicted proteins, which can be used to analyze and establish the PPI network of DEGs (9). Cytoscape (version 3.4.0; Cytoscape
User Support, Education and New Initiatives are supported by the National Resource for Network Biology; award no. P41 GM103504) is an open source bioinformatics software platform for visualizing molecular interaction networks (10). The Cytoscape plugin MCODE is an application for cluster analysis (11). With Cytoscape, a visualization of the molecular functions of DEGs can be obtained. Using the clustering analytic function of MCODE, the most significant module in a PPI network of DEGs was obtained; the hub genes were derived from this module.

Hub gene selection and analysis. After obtaining the most significant module in the PPI network of DEGs, genes with a score $\geq 3$ were selected as hub genes. PubMed Gene was employed to perform functional description of the hub genes (www.ncbi.nlm.nih.gov/gene/). The cBioPortal (www. cbioportal.org) platform was used to establish a network relationship between the hub genes and their co-expressed genes. The Cytoscape plugin BiNGO was used to visualize the BP of hub genes (12). The University of California Santa Cruz (UCSC) Cancer Genomics Browser (https://genome-cancer. ucsc.edu/) is a genomic database containing $>22,700$ shares of sample information (13). Users can explore the relationships between genomic changes and clinical phenotypes using visualized clinical data and phenotypic characteristics, such as age, tissue grade and pathology subtypes. Hierarchical clustering analysis of hub genes by the USCS Cancer Genomics Browser can identify the differential expression of hub genes between tumors and normal samples. The analysis can evaluate whether hub genes could be used as diagnostic markers.

To assess the potential function of hub genes in clinical progression of ACC, the prognostic analysis and clinical correlation analysis were performed. Overall survival rate and disease-free survival rate in ACC were analyzed using cBioPortal. Oncomine (www.oncomine.org) was used to further verify whether the expression of hub genes between ACC and normal tissues was significant different $(\mathrm{P}<0.05)$ and to evaluate the relationships between expression of hub genes and clinical phenotypes, including capsular invasion, grade and vascular invasion. The clinical correlation analysis is based on the Kolmogorov-Smirnov test. During the verification of Oncomine database, we set the following parameters: i) Analysis type, cancer vs. normal analysis; ii) cancer type, adrenal cortex carcinoma; and iii) data type, mRNA.

\section{Results}

Identification of DEGs in ACC. In the present study, 'Adrenocortical carcinoma', 'Adrenal cortical carcinoma' and 'Adrenal carcinoma' were used as the search terms for the GEO database. Initially, 815 studies were obtained. Subsequently, 29 studies were obtained through study type filter (set as expression profiling by array), of which only nine were of human tissue origin and the rest were animal or cytological experiments. In the residual nine studies, GSE90713 involved metastatic ACC samples and GSE73417 involved a neoplastic transplant model. GSE19776, GSE19775, GSE28476 and GSE15918 did not include compared normal tissues. Thus, only three datasets were ultimately selected. 


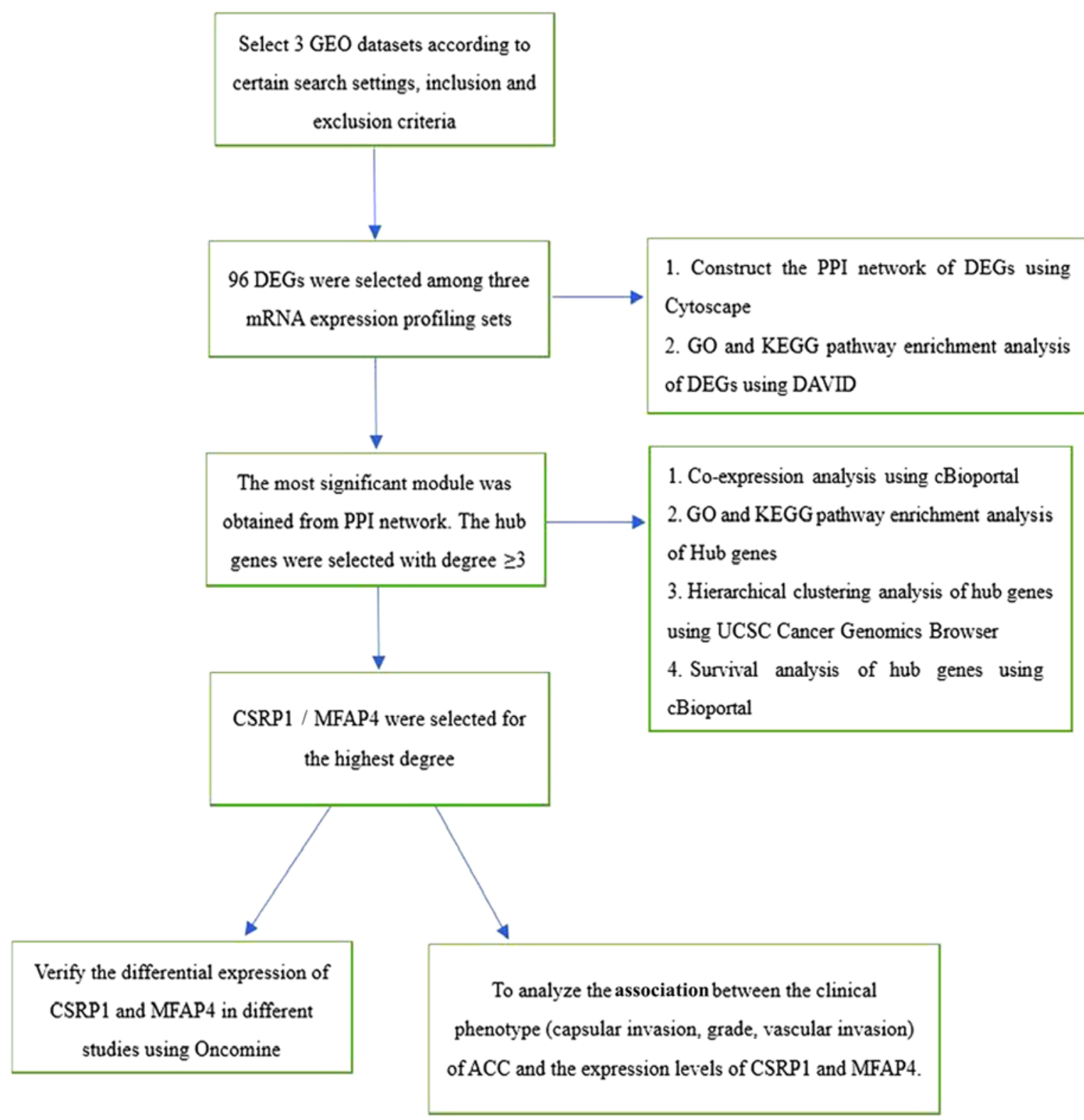

Figure 1. Research process. DEG, differentially expressed gene; PPI, protein-protein interaction; GO, Gene Ontology; CSRP1, cysteine and glycine rich protein 1; MFAP4, microfibril associated protein 4; GEO, Gene Expression Omnibus; KEGG, Kyoto Encyclopedia of Genes and Genomes; DAVID, Database for Annotation, Visualization and Integrated Discovery; UCSC, University of California Santa Cruz.

Finally, three datasets from the GEO database were selected according to the aforementioned criteria: i) GSE19750 (44 ACC; 4 normal); ii) GSE12368 (28 ACC; 6 normal); and iii) GSE14922 (4 ACC; 4 normal; 4 non-functioning adenomas; 4 secretory type). DEGs were identified in each dataset. In total, 1,464, 764 and 1,088 DEGs were identified in GSE19750, GSE12368 and GSE14922, respectively. As a result, 96 DEGs were shared across all three datasets (Fig. 2A).

$G O$ and KEGG enrichment analysis of DEGs. DAVID ver. 6.8 was used to perform GO and KEGG enrichment analyses for all identified DEGs. The pathways with $\mathrm{P}<0.05$ and the highest enrichment, based on the number of enriched genes, are presented in Table I. The CCs associated with the DEGs in the present study were mainly extracellular structures, including 'extracellular exosome', 'extracellular region' and 'extracellular space'. The MFs of these DEGs were predominantly associated with functional binding, including 'actin binding' and 'integrin binding'. Moreover, DEGs were found to be related with some tumor biological process, such as 'cell adhesion', 'muscle contraction' and 'negative regulation of inflammatory response'. According to the KEGG signaling pathway analysis, DEGs were significantly enriched in 'drug metabolism-cytochrome P450' and the 'pertussis' pathways.

PPI network and module analysis. Cytoscape (version 3.4.0) was used to construct a PPI network of DEGs (Fig. 2B). MCODE was used to extract the most significant module from the PPI network (Fig. 2C). The MCODE parameters were the following: i) Degree cut-off $=2$; ii) node score cut-off $=0.2$; iii) max depth $=100$; and iv) $\mathrm{k}$-score $=2$ (11). The most prominent module had 8 nodes and 14 edges. DAVID was used to perform GO and KEGG enrichment analyses of the module (Table II). The genes in this most prominent module were not 
A

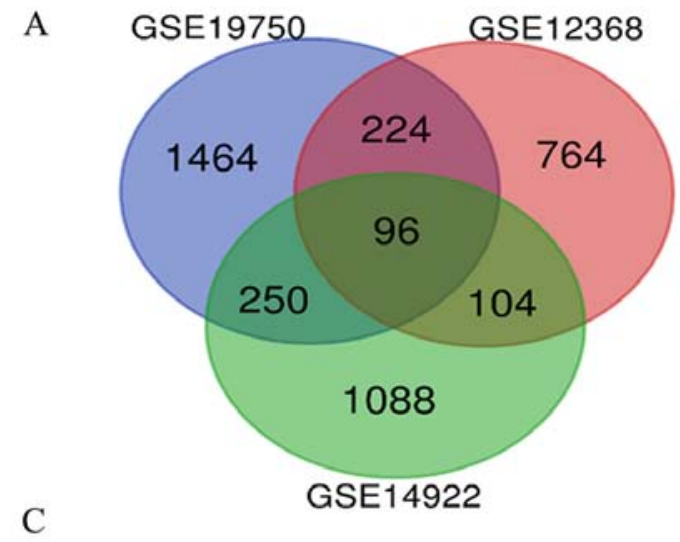

$\mathrm{C}$

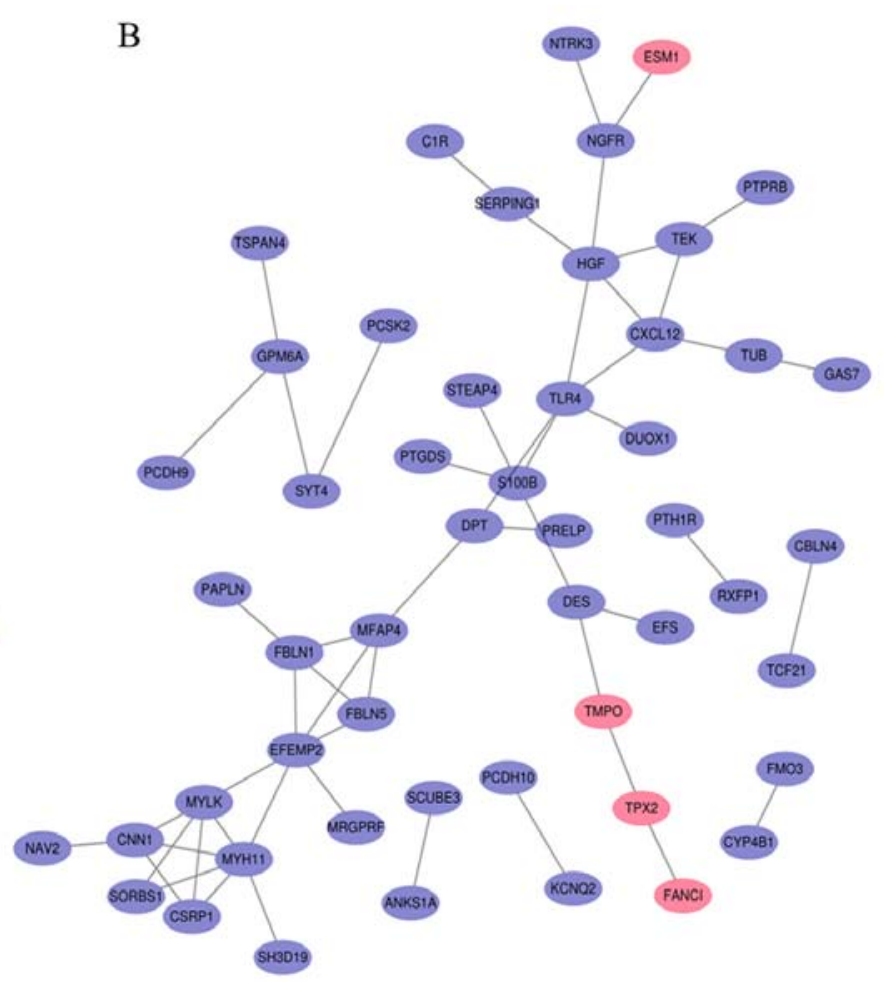

Figure 2. Venn diagram, PPI network and the most significant module of DEGs. (A) DEGs were selected among the mRNA expression profiling sets GSE19750, GSE12368 and GSE14922. The three datasets showed an overlap of 96 genes. (B) PPI network of DEGs was constructed using Cytoscape. (C) Most significant module was obtained from PPI network with 8 nodes and 14 edges. Upregulated genes are shown in red and downregulated genes are marked in blue. DEG, differentially expressed gene; PPI, protein-protein interaction.

significantly enriched in KEGG pathway analysis $(\mathrm{P}>0.05)$. In the GO analysis, the module was mainly enriched in some extracellular functions and structures, such as the 'extracellular exosome', 'extracellular region', 'elastic fiber' and 'elastic fiber assembly'.

Hub gene selection and analysis. The DEGs were selected as hub genes if their cluster degrees were $\geq 3.0$ in the MCODE analysis. A total of eight hub genes were identified, all of which were contained in the most significant module. PubMed Gene was used to obtain the corresponding gene names, abbreviations and functions (Table III). The cBioportal online tool was used to construct a co-expressed gene network of the hub genes (Fig. 3) and the BP visualization network of the hub genes was completed via BiNGO (Fig. 4). Using UCSC for hierarchical clustering analysis, the hub genes displayed low expression in tumor tissues, compared with normal tissues (Fig. 5).

Changes in the expression of all hub genes did not affect overall survival rate (Fig. 6). However, alteration of EGF containing fibulin extracellular matrix protein 2 (EFEMP2) led to a decline in disease-free survival rate.

The hub genes, cysteine and glycine rich protein 1 (CSRP1) and microfibril associated protein 4 (MFAP4), showed the highest node degree of 5, suggesting that these genes may have important functions in ACC carcinogenesis and progression. Subsequently, further verification was carried out via the Oncomine database. CSRP1 and MFAP4 were significantly downregulated in different studies $(14,15)$ (Fig. 7). Among these studies $(14,15)$, only Giordano et al's study (14) was provided with sufficient information of clinicopathological features (including capsular invasion, histological grade and vascular invasion), hence, which was used to perform clinical correlation analysis. The results revealed that lower mRNA levels of CSRP1 and MFAP4 were associated with adverse capsular invasion, grade and vascular invasion (Fig. 8).

\section{Discussion}

The incidence of ACC is low; however, due to its high potential for malignancy and metastasis, the 5-year survival rate of patients is only $16-47 \%$ (16). In addition, ACC is difficult to diagnose, even with imaging, hormone tests and postoperative diagnostic methods. Therefore, understanding the mechanisms of carcinogenesis and progression in ACC is of great importance to search for potential diagnostic markers and therapeutic targets.

Microarray technology has enabled assessment of genetic expression changes in ACC, which has provided insight into the molecular mechanism of this disease and has already been used extensively in cancer research. In the present study, three ACC mRNA matrix datasets from the GEO database were screened, allowing the identification of 96 DEGs. Enrichment analysis indicated that these DEGs were associated with some tumor-related BPs, such as 'cell adhesion' and 'negative regulation of inflammatory response' and may regulate ACC tumorigenesis and progression through the binding to other functional proteins (calcium-binding proteins, actin and integrin). In addition, the major functional region of these 
Table I. GO and KEGG enrichment analysis of differentially expressed genes.

A, Cellular component

\begin{tabular}{llcr}
\hline Term & \multicolumn{1}{c}{ Description } & Count in gene set & P-value \\
\hline GO:0070062 & Extracellular exosome & 26 & 0.0019 \\
GO:0005576 & Extracellular region & 20 & 0.0003 \\
GO:0005615 & Extracellular space & 17 & 0.0008 \\
\hline
\end{tabular}

B, Molecular function

\begin{tabular}{llcc}
\hline Term & \multicolumn{1}{c}{ Description } & Count in gene set & P-value \\
\hline GO:0005509 & Calcium ion binding & 12 & 0.0007 \\
GO:0003779 & Actin binding & 6 & 0.010 \\
GO:0005178 & Integrin binding & 4 & 0.0150 \\
\hline
\end{tabular}

C, Biological process

\begin{tabular}{llrr}
\hline Term & \multicolumn{1}{c}{ Description } & Count in gene set & P-value \\
\hline GO:0007155 & Cell adhesion & 8 & 0.0092 \\
GO:0006936 & Muscle contraction & 5 & 0.0022 \\
GO:0050728 & Negative regulation of inflammatory & 4 & 0.0078 \\
& response & &
\end{tabular}

D, KEGG pathway

\begin{tabular}{llrr}
\hline Term & \multicolumn{1}{c}{ Description } & Count in gene set & P-value \\
\hline Hsa00982 & Drug metabolism-cytochrome P450 & 3 & 0.0395 \\
Hsa05133 & Pertussis & 3 & 0.0471
\end{tabular}

GO, Gene Ontology; KEGG, Kyoto Encyclopedia of Genes and Genomes.

regulatory processes appeared to be extracellular locations. Cell adhesion is mediated by adhesion molecules, including members of the immunoglobulin superfamily and the integrin family. Integrins have crucial activities in regulating immune cell function, including transport of immune cells into tissues, activation of effector cells and formation of immune synapses between immune cells and tumor cells (14). Therefore, research on integrins is an active field in basic oncology. The present study identified that DEGs were significantly enriched in integrin regulation, suggesting that the selected DEGs play a crucial role in ACC carcinogenesis and progression.

The inflammatory response is also closely related to tumor progression. Although the immune system can recognize and kill tumor cells, the inflammatory response induced by immunization can also promote the proliferation of tumor cells and inhibit the anticancer response (17). Thus, inflammatory processes, as well as major metabolites involved in inflammation, including adiponectin and high-density lipoprotein, are strongly associated with the risk and invasiveness of solid tumors (18-20). The GO enrichment analysis also demonstrated that DEGs are involved in 'negative regulation of inflammatory response' (Table I). However, the concrete inflammatory regulatory mechanisms of DEGs relied on further research. In summary, the enrichment analysis results of the current study are consistent with previous oncology research $(12,21)$.

Using MCODE, the most significant module in the PPI network was obtained and eight hub genes with degree $\geq 3$ were identified. The hub genes identified in the present study were all downregulated in ACC, compared with normal tissue. This result was not in agreement with a previous study by Xiao et al (22). Several reasons might account for this difference. A possibility is the use of different study groups. From six datasets in the GEO database, Xiao et al (22) considered DNA topoisomerase II $\alpha$ (TOP2A), NDC80 kinetochore complex component, centrosomal protein 55, cyclin-dependent kinase inhibitor 3 and cyclin-dependent kinase 1, as five key genes that affect the progression and prognosis of ACC. In their analysis, the specimens of GSE33371 were from breast cancer and the specimens of GSE75415 were from adrenal cortical tumors of children. The dataset selection in the current study, 
Table II. GO enrichment analysis of differentially expressed genes in the most significant module.

A, Cellular component

\begin{tabular}{llll}
\hline Term & \multicolumn{1}{c}{ Description } & Count in gene set & P-value \\
\hline GO:0070062 & Extracellular exosome & 7 & $8.15 \times 10^{-5}$ \\
GO:0005576 & Extracellular region & 4 & 0.0183 \\
GO:0071953 & Elastic fiber & 3 & $7.59 \times 10^{-7}$ \\
\hline
\end{tabular}

B, Molecular function

\begin{tabular}{llrr}
\hline Term & \multicolumn{1}{c}{ Description } & Count in gene set & P-value \\
\hline GO:0005516 & Calmodulin binding & 3 & 0.0025 \\
GO:0005509 & Calcium ion binding & 3 & 0.0328 \\
GO:0005201 & Extracellular matrix structural constituent & 3 & 0.0274 \\
\hline
\end{tabular}

C, Biological process

\begin{tabular}{llcc}
\hline Term & \multicolumn{1}{c}{ Description } & Count in gene set & P-value \\
\hline GO:0048251 & Elastic fiber assembly & 3 & $2.23 \times 10^{-6}$ \\
GO:0006939 & Smooth muscle contraction & 2 & 0.0064 \\
GO:0006936 & Muscle contraction & 2 & 0.0376
\end{tabular}

GO, Gene Ontology.

Table III. Functional roles of hub genes.

\begin{tabular}{|c|c|c|}
\hline Gene & Full name & Function \\
\hline CNN1 & Calponin 1 & $\begin{array}{l}\text { Cell proliferation, anchorage-independent colony formation, cell } \\
\text { motility and invasion. }\end{array}$ \\
\hline CSRP1 & Cysteine and glycine rich protein 1 & A growth factor, cell proliferation, somatic differentiation. \\
\hline MYLK & Myosin light chain kinase & $\begin{array}{l}\text { Catalyze the phosphorylation of myosin light chains (MLC), cell inva- } \\
\text { sion and metastasis. }\end{array}$ \\
\hline MYH11 & Myosin heavy chain 11 & $\begin{array}{l}\text { Hydrolysis of ATP, cell migration and adhesion, intracellular transport, } \\
\text { signal transduction. }\end{array}$ \\
\hline EFEMP2 & $\begin{array}{l}\text { EGF containing fibulin } \\
\text { extracellular matrix protein } 2\end{array}$ & $\begin{array}{l}\text { Blood coagulation, activation of complement, determination of cell fate } \\
\text { during development. }\end{array}$ \\
\hline FBLN1 & Fibulin 1 & Cell adhesion, migration, differentiation. \\
\hline MFAP4 & Microfibril associated protein 4 & Cell adhesion, intercellular interactions. \\
\hline FBLN5 & Fibulin 5 & $\begin{array}{l}\text { Angiogenesis, epithelial cell motility, the activity of matrix metallopro- } \\
\text { tease } 9 \text { (MMP-9). }\end{array}$ \\
\hline
\end{tabular}

however, involved a different study group. Alternatively, differences in preliminary screening of the mRNA expression datasets could also explain the discrepancies between the two studies. Unlike the previous study by Xiao et al (22), a preliminary screening of the mRNA datasets was conducted before obtaining the DEGs. The criteria were $\operatorname{LogFC} \geq 0.5$ and $\mathrm{P}<0.01$, to ensure that the genes entering the analysis reached the pre-set threshold for statistical significance. Thus, differ- ences in screening conditions and analysis likely explain the different results between previous research and the present study.

Compared with upregulated hub genes identified in previous studies, the present results suggested that downregulated hub genes are also important in carcinogenesis. The following descriptions of the ACC-associated downregulated genes speculated how they may contribute to ACC onset. 


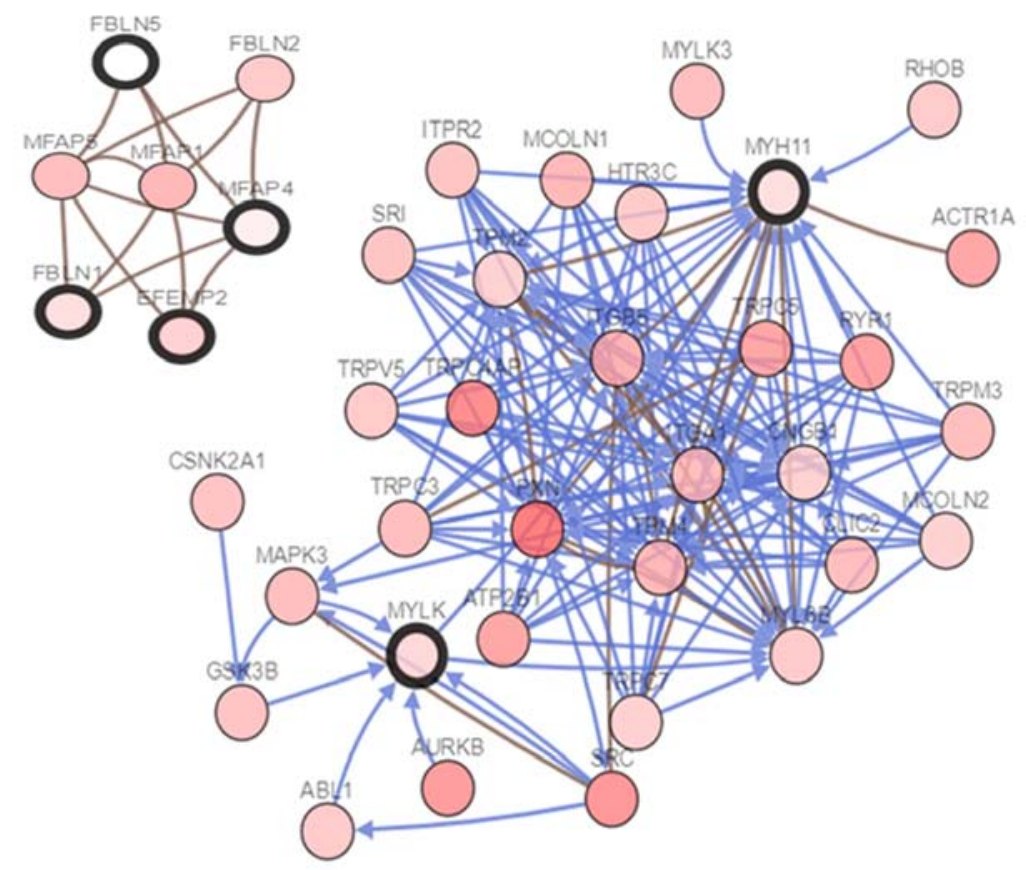

Figure 3. Network between hub genes and their co-expressed genes. Nodes with bold black outlines represent hub genes. Nodes with thin black outlines represent the co-expressed genes.

In ovarian cancer, calponin 1 (CNN1) is an important tumor suppressor gene (23). Low expression of CNN1 in peritumoral vessels is negatively related to the expression of vascular endothelial growth factor, which is involved in the generation of tumor blood vessels (24). In addition, CNN1 was associated with the progression and prognosis of bladder cancer in a previous study (25).

CSRP1 and MFAP4 are expressed at low levels in some tumors, yet this was shown to have different consequences in different tumor types or stages. CSRP1 was hypothesized to be a tumor suppressor gene in colorectal cancer (26). In addition, CSRP1 may be inactivated due to abnormal methylation and may be an important diagnostic marker for liver cancer (27). However, celecoxib may exhibit anti-gastric cancer effects by suppressing expression of CSRP1 (28). In the present study, CSRP1 was downregulated in ACC, which indicated that CSRP1 may be a tumor suppressor gene. MFAP4 is a tumor suppressor gene in prostate cancer and it displays low expression in breast cancer $(29,30)$. By contrast, downregulated MFAP4 may lead to adverse clinical incidents in ovarian cancer (31). This contradiction may be explained by the fact that, in early stage cancer, MFAP4 facilitates inflammatory cell recruitment and assists immunological cancer surveillance to restrain cancer cell survival (32). However, in advance stage, alteration of the tumor microenvironment results in decreased immune function of lymphocytes and MFAP4 predominantly promoted cancer cell proliferation and migration (33). Similarly, it's putative that low expression of MFAP4 ineffectively activate immune and inflammatory cells to suppress malignant progression of ACC.

Fibulin (FBLN) 1 and -5 belong to the FBLN protein family, which is involved in maintaining the stability of the basal membrane, elastic fibers and loose connective tissue. Schluterman et al (34) demonstrated that loss of fibulin 5
(FBLN5) expression promoted tumor progression by increasing the level of reactive oxygen species. In most human carcinomas, especially in kidney, breast, ovarian, colon and malignant metastatic carcinoma, FBLN5 was downregulated compared with normal tissues (35). In addition, FBLN5 is also a target for transforming growth factor $\beta$ in endothelial cells, suggesting that FBLN5 may be a therapeutic target (36).

The myosin heavy chain 11 (MYH11) gene encodes the smooth muscle myosin heavy chain and mutations in MYH11 were mainly associated with aortic aneurysm and acute myeloid leukemia (37,38). Carcinoma metastasis and invasion are driven by cell movement, a process involving myosin/actin contraction and cell contact point degradation (39). Mutation and downregulation of MYH11 were associated with colon cancer and mucosal polyp syndrome (40). MYH11 was also downregulated in breast and bladder carcinoma (41).

EFEMP2 is an extracellular matrix protein necessary for elastic fiber formation and connective tissue development, processes that are highly associated with tumor invasion and metastasis (42). The expression of EFEMP2 in bladder cancer tissues was significantly lower than that in normal tissues in previous study (43). Zhou et al (43) confirmed that low expression of EFEMP2 could reduce the expression of epithelial marker E-cadherin, as well as increase the expressive levels of mesenchymal markers $\mathrm{N}$-cadherin, vimentin, Snail and Slug and key factors of the Wnt $/ \beta$-catenin signaling pathway ( $\beta$-catenin, c-Myc and cyclin D1). Their observations demonstrated that EFEMP2 inhibited tumor progression and metastasis in bladder cancer (43). However, to the best of our knowledge, studies on EFEMP2 in ACC have not yet been performed; thus, the findings of the present study may provide insight for adrenocortical tumorigenesis.

Myosin light chain kinase (MYLK) regulates myosin activity through phosphorylation and dephosphorylation of 


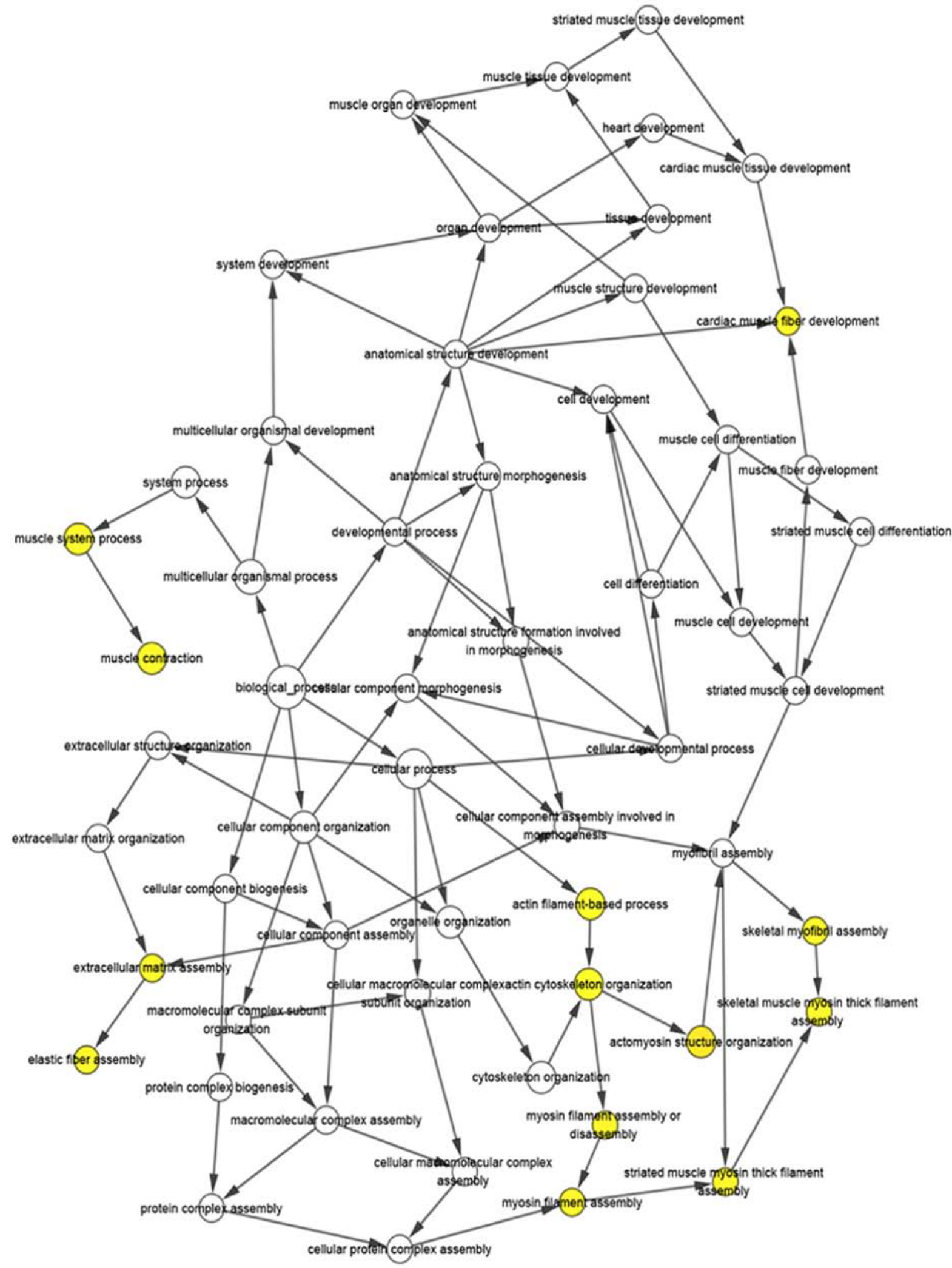

Figure 4. Visualized biological process analysis of hub genes. The color depth of the nodes refers to the corrected P-value of ontologies. The size of the nodes refers to the numbers of enriched genes. Yellow nodes represent Gene Ontology categories that are overrepresented at the significance level. P $<0.01$ was used to indicate statistically significant difference.

the myosin light chain. Therefore, it is involved in many physiological processes, such as cell adhesion, cell proliferation, cell migration and infiltration (44). MYLK can increase the expression of epidermal growth factor receptor and activate the ERK/JNK signal pathway, which can ablate the adhesion between cells and increase the aggressiveness of breast cancer cells (45). In addition, MYLK expression is low in prostate cancer, bladder cancer, non-small cell carci- 


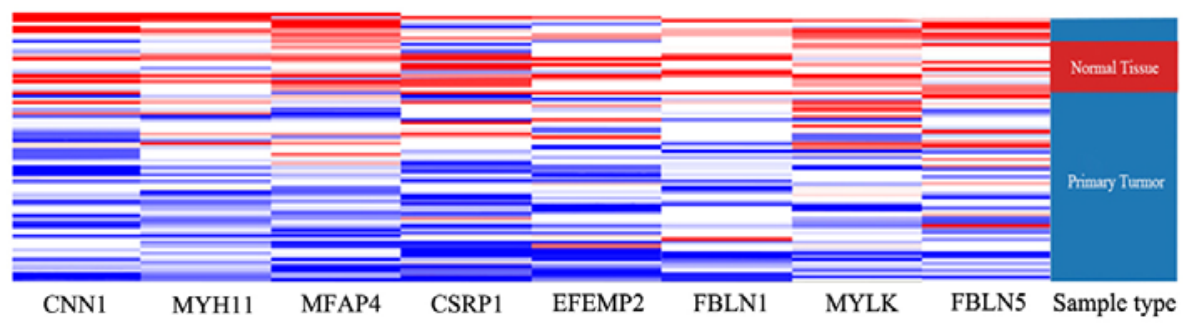

Figure 5. Hierarchical clustering of hub genes was constructed using University of California Santa Cruz. The samples under the red bar are non-cancerous samples and the samples under the blue bar are adrenocortical carcinoma samples. Upregulation of genes is marked in red; downregulation of genes is marked in blue. CNN1, calponin 1; CSRP1, cysteine and glycine rich protein 1; MYLK, myosin light chain kinase; MHY11, myosin heavy chain 11; EFEMP2, EGF containing fibulin extracellular matrix protein 2; FBLN1, fibulin 1; MFPA4, microfibril associated protein 4; FBLN5, fibulin 5.

Cases with alteration(s) in query gene(s)

- Cases without alteration(s) in query gene(s)
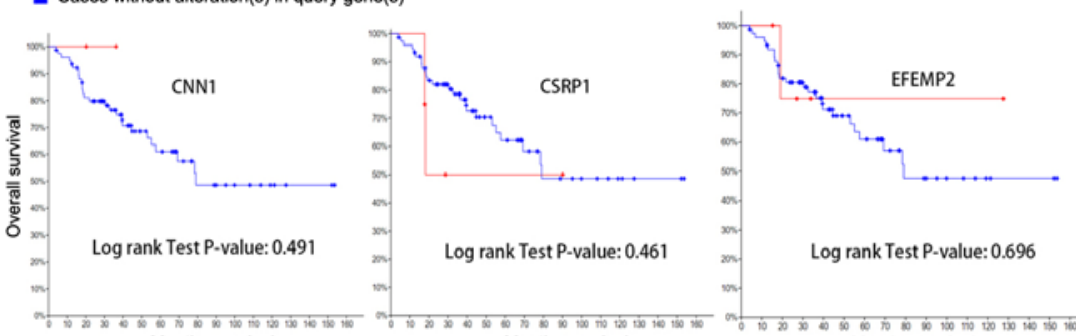

Log rank Test P-value: 0.461

Log rank Test P-value: 0.696
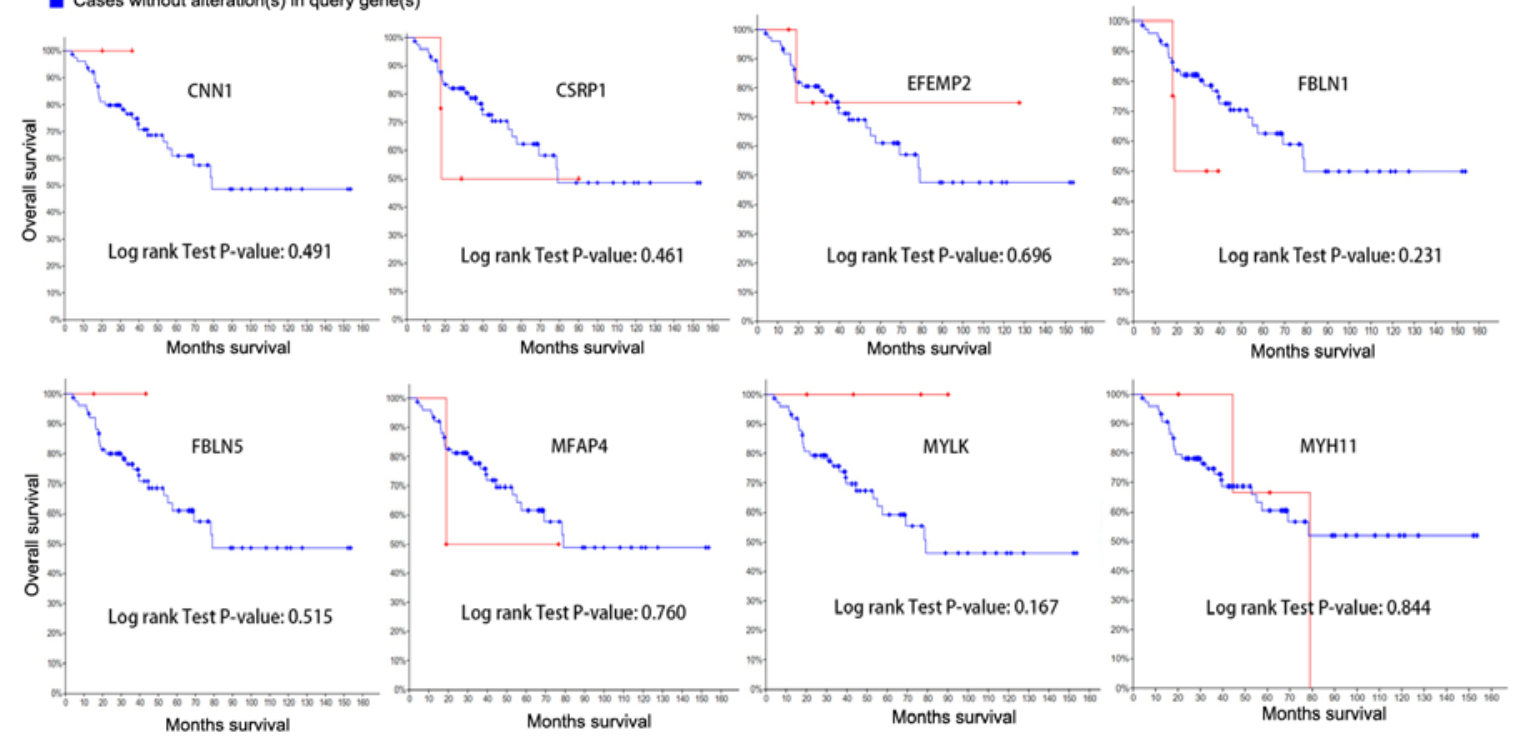

B
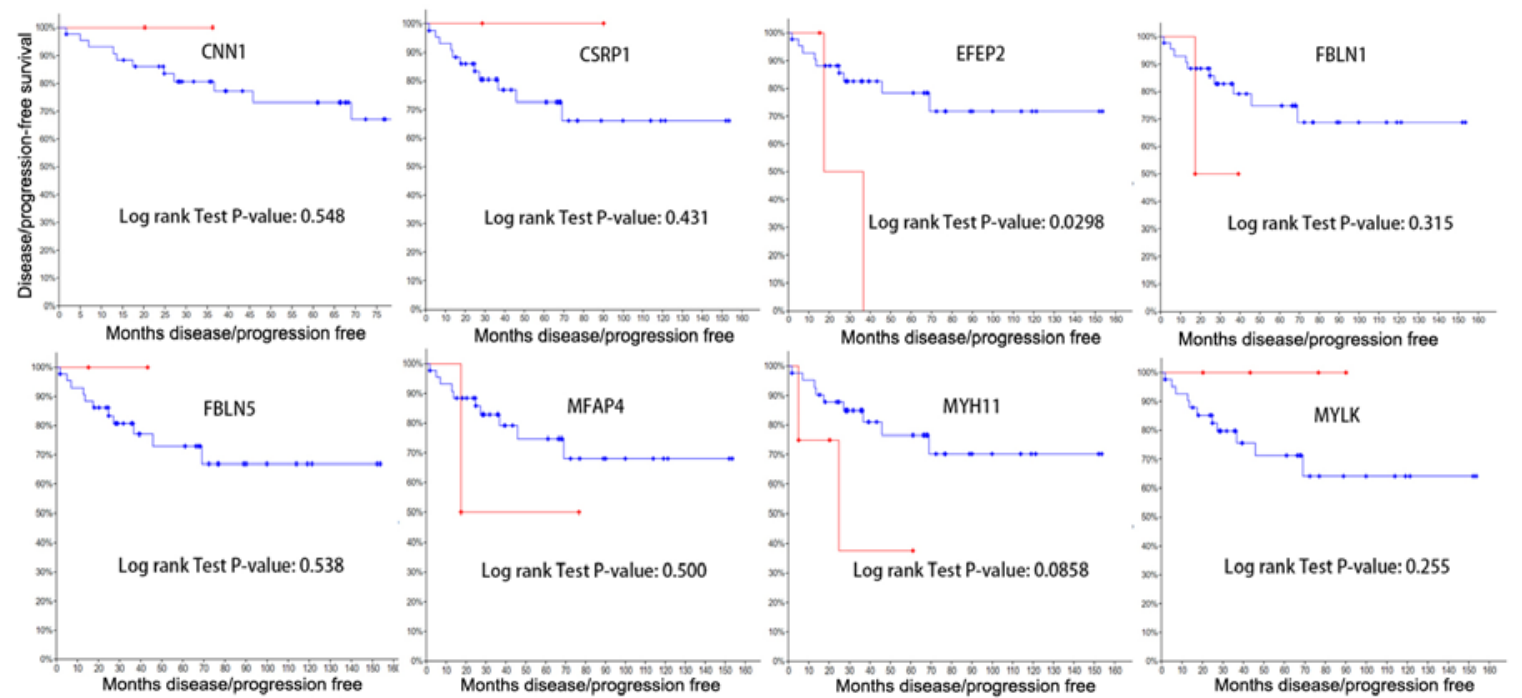

Figure 6. Survival analysis of hub genes. (A) Overall survival and (B) disease-free survival analyses of hub genes were performed using cBioPortal online platform. $\mathrm{P}<0.05$ was used to indicate a statistically significant difference. CNN1, calponin 1; CSRP1, cysteine and glycine rich protein 1; MYLK, myosin light chain kinase; MHY11, myosin heavy chain 11; EFEMP2, EGF containing fibulin extracellular matrix protein 2; FBLN1, fibulin 1; MFPA4, microfibril associated protein 4; FBLN5, fibulin 5.

noma and gastric cancer, which indicates this gene may greatly impact on carcinogenesis and malignant progression $(46,47)$.
ACC is difficult to diagnose, even with postoperative pathological analysis. Previous studies and published guidelines (48-50) indicated that histopathological features alone 


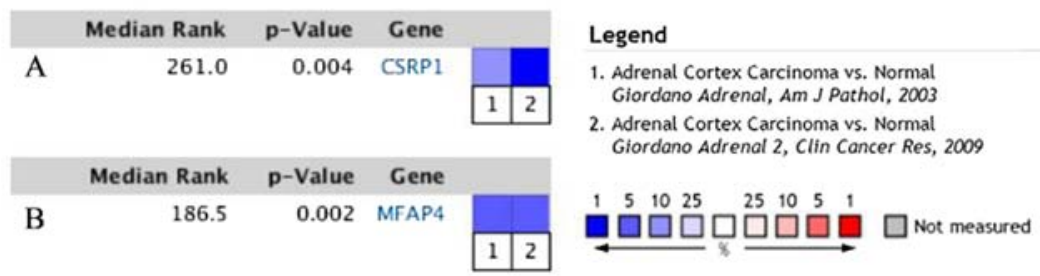

Figure 7. Oncomine analysis of cancer and normal tissue. (A) CSRP1 heatmap. (B) MFAP4 heatmap. The heatmaps reveal the differetial expression of CSRP1 and MFAP4 between clinical ACC samples and normal tissues. CSRP1, cysteine and glycine rich protein 1; MFPA4, microfibril associated protein 4.

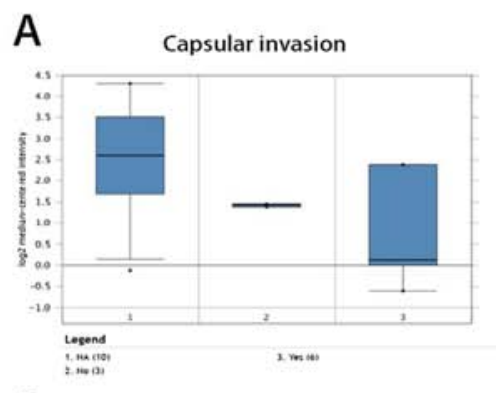

B

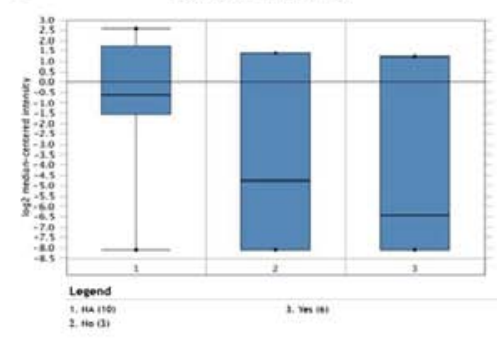

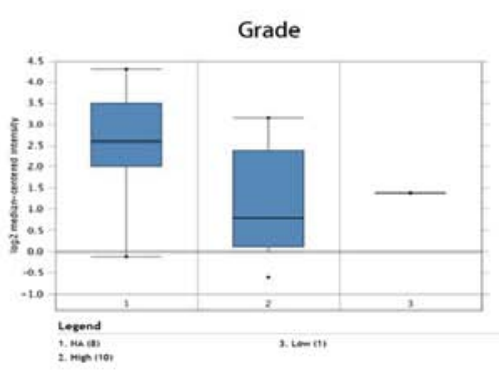

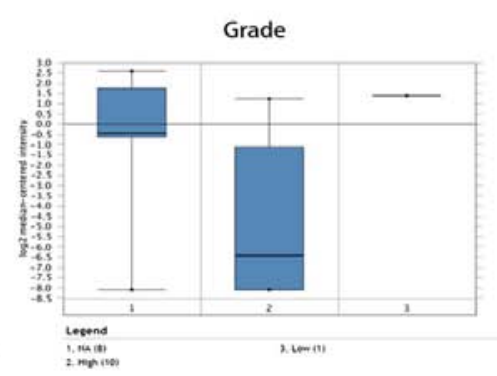

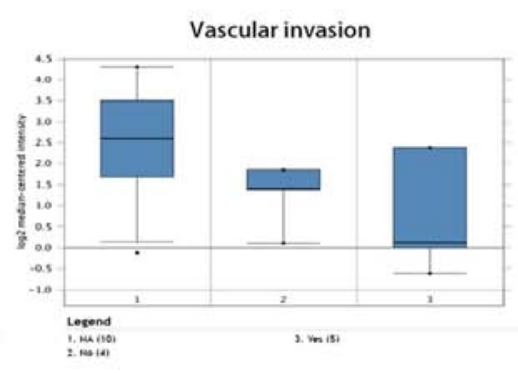

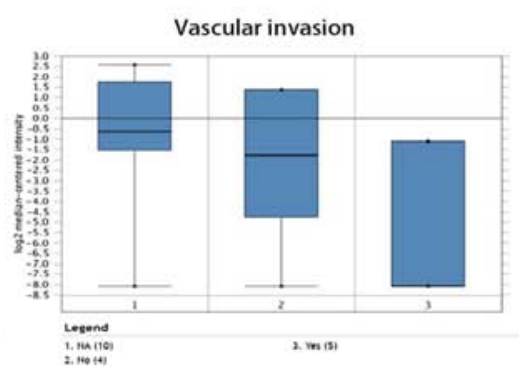

Figure 8. Association between the expression level of CSRP1 and MFAP4 and capsular invasion, grade and vascular invasion in the Giordano et al (14) adrenal dataset. (A) CSRP1 mRNA expression in ACC, compared with normal adrenal tissues. (B) MFAP4 mRNA expression in ACC samples. CSRP1, cysteine and glycine rich protein 1; MFPA4, microfibril associated protein 4; ACC, adrenocortical carcinoma.

cannot predict malignant or metastatic occurrence and that regular and long-term follow-up is necessary for most cases. Thus, there is a clear need to find rapid and accurate tools for diagnosis of adrenocortical cancer.

Certain previous studies have revealed that Ki-67 and minichromosome maintenance protein are reliable indicators of benign and malignant adrenal tumors $(51,52)$. Additionally, various studies have used pituitary-tumor transforming gene 1 (53), telomerase activity (54) and vascular endothelial growth factor (55) as diagnostic markers of ACC. However, studies of these ACC diagnostic markers have not reached a uniform and reliable conclusion. Nowadays, gene expression analysis has been used to screen molecular markers for cancer diagnosis and prognosis. Microarray technology may become the method of choice for the detection of malignant adrenal tissue. In the present study, bioinformatics analysis was used to identify eight key downregulated genes. It was verified that these genes were associated with ACC in terms of molecular function, biological processes and cytology. Moreover, using cluster analysis in the USCS Cancer Genomics Browser, it was demonstrated that the selected hub genes can distinguish normal adrenal tissues from ACC tissues. However, there were many samples that did not display expression of the hub genes, which suggested that these hub genes are not differentially expressed in all ACC tissues. This condition will impose some limitations on diagnosis.

Analysis of the relationships between gene expression levels and clinical phenotypes is another important issue in oncology. Using Kaplan-Meier analysis, the association between overall survival rate, disease-free survival rate and the downregulated hub genes was assessed. This analysis showed that alterations of all hub genes did not affect overall survival rate. However, downregulated EFEMP2 resulted in a decrease on disease-free survival rate. The lack of effects on survival may be due to several reasons. Firstly, survival analyses in cBioPortal database were performed on the basis of the relationship between gene mutation and prognosis, whereas genetic low expression may result from promoter methylation, histone modification or protein acetylation, not just mutation. Thus, low expression of the eight hub genes in ACC may possessed low frequency of mutation, which led the prognostic difference insignificant. Other previous studies demonstrated a similar lack of conformity. For example, in bioinformatics analysis conducted by Li et al (56), the TOP2A oncogene did not affect overall and disease-free survival rates. However, some previous clinical studies demonstrated that TOP2A was significantly related to the survival rate of patients with hepatocellular carcinoma $(57,58)$. Secondly, carcinogenesis and progression of tumors are the result of multi-gene 
dysregulation and different genes can have various effects on tumor prognosis. Although the low-expression genes identified in ACC in the present study are involved in multiple key steps of tumorigenesis and progression, their effects on prognosis may be less than the effects of high-expression genes identified in previous studies $(22,59)$. Compared with other urologic neoplasms, ACC has a low incidence (0.7-2/million), which may lead the insufficiency of datasets and samples. Small sample size may skew the results of prognostic analysis (60).

Capsular invasion, histological grade and vascular invasion are common yet informative clinicopathological parameters. These indicators can reflect the tendency of tumor progression and reveal the differentiated degree of neoplasms. Thus, several previous studies have analyzed the relationships between gene expression and these clinical parameters in different cancer, such as hepatocellular carcinoma, thyroid carcinoma and pheochromocytoma (61-63). Therefore, these clinicopathological features are commonly used in cancer research. In the present study, the expression levels of CSRP1 and MFAP4 were associated with capsular invasion, grade and vascular invasion, which suggested that CSRP1 and MFAP4 may promote progression of ACC.

The present study also has some limitations. First, the clinical data of ACC are insufficient. Due to the low incidence of ACC, there were few qualified datasets for bioinformatics analysis. Moreover, subtypes of ACC were not considered in the bioinformatics analysis. The main subtype of ACC is adrenal epithelial cell carcinoma, which accounts for $>95 \%$ of all subtypes. Other rare subtypes include oncocytic adrenal neoplasms, myxoid adrenal cortical carcinoma and adrenal carcinosarcoma. Different subtypes may have different mechanisms of carcinogenesis and progression, but there is a lack of data and relevant research to verify this possibility.

In conclusion, the hub genes screened in the present study were downregulated and these genes were associated with ACC carcinogenesis and progression. Identification of these hub genes improves the gene expression profile of ACC and provides important molecular biological insight for the diagnosis, treatment and prognosis of ACC. Nevertheless, further studies are needed to elucidate how the biological functions of these genes contribute to ACC.

\section{Acknowledgements}

Not applicable.

\section{Funding}

No funding was received.

\section{Availability of data and materials}

The datasets used and/or analyzed during the current study are available from the corresponding author on reasonable request.

\section{Authors' contributions}

TC designed the study and revised the manuscript. FX performed the Gene Expression Omnibus database analysis, analyzed the data. FX and PZ performed bioinformatics analyses and assisted with analysis of other data. FX, MY and $\mathrm{XY}$ wrote the manuscript, collected data, performed revision of the manuscript and created the figures. All authors have read and approved the manuscript.

\section{Ethics approval and consent to participate}

Not applicable.

\section{Patient consent for publication}

Not applicable.

\section{Competing interests}

The authors declare that they have no competing interests.

\section{References}

1. Erickson LA, Rivera M and Zhang J: Adrenocortical carcinoma: Review and update. Adv Anat Pathol 21: 151-159, 2014.

2. Stigliano A, Cerquetti L, Lardo P, Petrangeli E and Toscano V: New insights and future perspectives in the therapeutic strategy of adrenocortical carcinoma (Review). Oncol Rep 37: 1301-1311, 2017.

3. Wang HW, Wu YH, Hsieh JY, Liang ML, Chao ME, Liu DJ, Hsu MT and Wong TT: Pediatric primary central nervous system germ cell tumors of different prognosis groups show characteristic miRNome traits and chromosome copy number variations. BMC Genomics 11: 132, 2010.

4. Soon PS, Gill AJ, Benn DE, Clarkson A, Robinson BG, McDonald KL and Sidhu SB: Microarray gene expression and immunohistochemistry analyses of adrenocortical tumors identify IGF2 and Ki-67 as useful in differentiating carcinomas from adenomas. Endocr Relat Cancer 16: 573-583, 2009.

5. Szabó PM, Wiener Z, Tömböl Z, Kovács A, Pócza P, Horányi J, Kulka J, Riesz P, Tóth M, Patócs A, et al: Differences in the expression of histamine-related genes and proteins in normal human adrenal cortex and adrenocortical tumors. Virchows Arch 455: 133-142, 2009.

6. Gene Ontology Consortium: Gene ontology consortium: Going forward. Nucleic Acids Res 43 (Database Issue): D1049-D1056, 2015.

7. Kanehisa M, Goto S, Furumichi M, Tanabe M and Hirakawa M: KEGG for representation and analysis of molecular networks involving diseases and drugs. Nucleic Acids Res 38 (Database Issue): D355-D360, 2010.

8. Huang DW, Sherman BT, Tan Q, Collins JR, Alvord WG, Roayaei J, Stephens R, Baseler MW, Lane HC and Lempicki RA: The DAVID gene functional classification tool: A novel biological module-centric algorithm to functionally analyze large gene lists. Genome Biol 8: R183, 2007.

9. Franceschini A, Szklarczyk D, Frankild S, Kuhn M, Simonovic M, Roth A, Lin J, Minguez P, Bork P, von Mering C and Jensen LJ: STRING v9.1: Protein-protein interaction networks, with increased coverage and integration. Nucleic Acids Res 41 (Database Issue): D808-D815, 2013.

10. Shannon P, Markiel A, Ozier O, Baliga NS, Wang JT, Ramage D, Amin N, Schwikowski B and Ideker T: Cytoscape: A software environment for integrated models of biomolecular interaction networks. Genome Res 13: 2498-2504, 2003.

11. Rivera CG, Vakil R and Bader JS: NeMo: Network module identification in cytoscape. BMC Bioinformatics 11: S61, 2010.

12. Maere S, Heymans K and Kuiper M: BiNGO: A Cytoscape plugin to assess overrepresentation of gene ontology categories in biological networks. Bioinformatics 21: 3448-3449, 2005.

13. Goldman M, Craft B, Swatloski T, Ellrott K, Cline M, Diekhans M, Ma S, Wilks C, Stuart J, Haussler D and Zhu J: The UCSC cancer genomics browser: Update 2013. Nucleic Acids Res 41 (Database Issue): D949-D954, 2013. 
14. Giordano TJ, Thomas DG, Kuick R, Lizyness M, Misek DE, Smith AL, Sanders D, Aljundi RT, Gauger PG, Thompson NW, et al: Distinct transcriptional profiles of adrenocortical tumors uncovered by DNA microarray analysis. Am J Pathol 162: 521-531, 2003.

15. Giordano TJ, Kuick R, Else T, Gauger PG, Vinco M, Bauersfeld J, Sanders D, Thomas DG, Doherty G and Hammer G: Molecular classification and prognostication of adrenocortical tumors by transcriptome profiling. Clin Cancer Res 15: 668-676, 2009.

16. Else T, Kim AC, Sabolch A, Raymond VM, Kandathil A, Caoili EM, Jolly S, Miller BS, Giordano TJ and Hammer GD: Adrenocortical carcinoma. Endocr Rev 35: 282-326, 2014.

17. Harjunpää H, Llort Asens M, Guenther C and Fagerholm SC: Cell adhesion molecules and their roles and regulation in the immune and tumor microenvironment. Front Immunol 10: 1078, 2019.

18. Revilla G, Corcoy R, Moral A, Escolà-Gil JC and Mato E: Cross-talk between inflammatory mediators and the epithelial mesenchymal transition process in the development of thyroid carcinoma. Int J Mol Sci 20: pii: E2466, 2019.

19. Antunes DM, Rodrigues MFSD, Guimarães DM, Duarte CME Miguita L, Corrêa L, DE Oliveira APL, Fernandes KPS and Nunes FD: Nonsteroidal anti-inflammatory drugs modulate gene expression of inflammatory mediators in oral squamous cell carcinoma. Anticancer Res 39: 2385-2394, 2019.

20. Qu X, Tang Y and Hua S: Immunological approaches towards cancer and inflammation: A cross talk. Front Immunol 9: 563, 2018.

21. Macciò A and Madeddu C: Blocking inflammation to improve immunotherapy of advanced cancer. Immunology 159: 357-364, 2020

22. Xiao H, Xu D, Chen $P$, Zeng G, Wang $X$ and Zhang $X$ : Identification of five genes as a potential biomarker for predicting progress and prognosis in adrenocortical carcinoma. J Cancer 9: 4484-4495, 2018

23. Yamane T, Asanoma K, Kobayashi H, Liu G, Yagi H, Ohgami T, Ichinoe A, Sonoda $\mathrm{K}$, Wake $\mathrm{N}$ and Kato K: Identification of the critical site of calponin 1 for suppression of ovarian cancer properties. Anticancer Res 35: 5993-5999, 2015.

24. Yanagisawa Y, Takeoka M, Ehara T, Itano N, Miyagawa S and Taniguchi S: Reduction of Calponin h1 expression in human colon cancer blood vessels. Eur J Surg Oncol 34: 531-537, 2008.

25. Liu Y, Wu X, Wang G, Hu S, Zhang Y and Zhao S: CALD1, CNN1, and TAGLN identified as potential prognostic molecular markers of bladder cancer by bioinformatics analysis. Medicine (Baltimore) 98: e13847, 2019.

26. Zhou CZ, Qiu GQ, Wang XL, Fan JW, Tang HM, Sun YH, Wang Q, Huang F, Yan DW, Li DW and Peng ZH: Screening of tumor suppressor genes on 1q31.1-32.1 in Chinese patients with sporadic colorectal cancer. Chin Med J (Engl) 121: 2479-2486, 2008.

27. Hirasawa Y, Arai M, Imazeki F, Tada M, Mikata R, Fukai K, Miyazaki M, Ochiai T, Saisho H and Yokosuka O: Methylation status of genes upregulated by demethylating agent 5-aza-2'-deoxycytidine in hepatocellular carcinoma. Oncology 71: 77-85, 2006.

28. Jin GH, Xu W, Shi Y and Wang LB: Celecoxib exhibits an anti-gastric cancer effect by targeting focal adhesion and leukocyte transendothelial migration-associated genes. Oncol Lett 12: 2345-2350, 2016.

29. Davalieva K, Kostovska IM, Kiprijanovska S, Markoska K, Kubelka-Sabit K, Filipovski V, Stavridis S, Stankov O, Komina S, Petrusevska G and Polenakovic M: Proteomics analysis of malignant and benign prostate tissue by 2D DIGE/ MS reveals new insights into proteins involved in prostate cancer. Prostate 75: 1586-1600, 2015.

30. Yang J, Song H, Chen L, Cao K, Zhang Y, Li Y and Hao X: Integrated analysis of microfibrillar-associated proteins reveals MFAP4 as a novel biomarker in human cancers. Epigenomics 11: 1635-1651, 2019.

31. Zhao H, Sun Q, Li L, Zhou J, Zhang C, Hu T, Zhou X, Zhang L, Wang B, Li B, et al: High expression levels of AGGF1 and MFAP4 predict primary platinum-based chemoresistance and are associated with adverse prognosis in patients with serous ovarian cancer. J Cancer 10: 397-407, 2019.

32. Niu D, Peatman E, Liu H, Lu J, Kucuktas H, Liu S, Sun F, Zhang H, Feng T, Zhou Z, et al: Microfibrillar-associated protein 4 (MFAP4) genes in catfish play a novel role in innate immune responses. Dev Comp Immunol 35: 568-579, 2011.
33. Schlosser A, Pilecki B, Hemstra LE, Kejling K, Kristmannsdottir GB, Wulf-Johanss on H, Moeller JB, Füchtbauer EM, Nielsen O, Kirketerp-Møller K, et al: MFAP4 promotes vascular smooth muscle migration, proliferation and accelerates neointima formation. Arterioscler Thromb Vasc Biol 36: 122-133, 2016.

34. Schluterman MK, Chapman SL, Korpanty G, Ozumi K, Fukai T, Yanagisawa $\mathrm{H}$ and Brekken RA: Loss of fibulin-5 binding to betal integrins inhibits tumor growth by increasing the level of ROS. Dis Model Mech 3: 333-342, 2010.

35. Dou CY, Cao CJ, Wang Z, Zhang RH, Huang LL, Lian JY, Xie WL and Wang LT: EFEMP1 inhibits migration of hepatocellular carcinoma by regulating MMP2 and MMP9 via ERK1/2 activity. Oncol Rep 35: 3489-3495, 2016.

36. Topalovski M, Hagopian M, Wang M and Brekken RA: Hypoxia and transforming growth factor $\beta$ cooperate to induce fibulin-5 expression in pancreatic cancer. J Biol Chem 291: 22244-22252, 2016.

37. Pannu H, Tran-Fadulu V, Papke CL, Scherer S, Liu Y, Presley C, Guo D, Estrera AL, Safi HJ, Brasier AR, et al: MYH11 mutations result in a distinct vascular pathology driven by insulin-like growth factor 1 and angiotensin II. Hum Mol Genet 16: 2453-2462, 2007

38. Assaf N, El-Cheikh J, Bazarbachi A, Salem Z, Farra C, Chakhachiro Z, Nassif S, Zaatari G and Mahfouz R: Molecular profiling of adult acute myeloid and lymphoid leukemia in a major referral center in Lebanon: A 10-year experience report and review of the literature. Mol Biol Rep 46: 2003-2011, 2019.

39. Friedl $\mathrm{P}$ and Wolf $\mathrm{K}$ : Tumour-cell invasion and migration: Diversity and escape mechanisms. Nat Rev Cancer 3: 362-374, 2003.

40. Lee WS, Seo G, Shin HJ, Yun SH, Yun H, Choi N, Lee J, Son D, Cho J, Kim J, et al: Identification of differentially expressed genes in microsatellite stable HNPCC and sporadic colon cancer. J Surg Res 144: 29-35, 2008.

41. Alhopuro P, Karhu A, Winqvist R, Waltering K, Visakorpi T and Aaltonen LA: Somatic mutation analysis of MYH11 in breast and prostate cancer. BMC Cancer 8: 263, 2008.

42. Song L, Li XX, Liu XY, Wang Z, Yu Y, Shi M, Jiang B and He XP: EFEMP2 suppresses the invasion of lung cancer cells by inhibiting epithelial-mesenchymal transition (EMT) and down-regulating MMPs. Onco Targets Ther 13: 1375-1396, 2020.

43. Zhou Q, Chen S, Lu M, Luo Y, Wang G, Xiao Y, Ju L and Wang X: EFEMP2 suppresses epithelial-mesenchymal transition via Wnt/ $\beta$-catenin signaling pathway in human bladder cancer. Int J Biol Sci 15: 2139-2155, 2019.

44. Khapchaev AY and Shirinsky VP: Myosin light Chain kinase MYLK1: Anatomy, interactions, functions, and regulation. Biochemistry (Mosc) 81: 1676-1697, 2016.

45. Kim DY and Helfman DM: Loss of MLCK leads to disruption of cell-cell adhesion and invasive behavior of breast epithelial cells via increased expression of EGFR and ERK/JNK signaling. Oncogene 35: 4495-4508, 2016.

46. Dai Y, Li D, Chen X, Tan X, Gu J, Chen M and Zhang X: Circular RNA myosin light chain kinase (MYLK) promotes prostate cancer progression through modulating Mir-29a expression. Med Sci Monit 24: 3462-3471, 2018

47. Zhong Z, Huang M, Lv M, He Y, Duan C, Zhang L and Chen J: Circular RNA MYLK as a competing endogenous RNA promotes bladder cancer progression through modulating VEGFA/ VEGFR2 signaling pathway. Cancer Lett 403: 305-317, 2017.

48. Nakamura Y, Yamazaki Y, Felizola SJ, Ise K, Morimoto R, Satoh F, Arai Y and Sasano H: Adrenocortical carcinoma: Review of the pathologic features, production of adrenal steroids, and molecular pathogenesis. Endocrinol Metab Clin North Am 44: 399-410, 2015.

49. Lowery AJ, Walsh S, McDermott EW and Prichard RS Molecular and therapeutic advances in the diagnosis and management of malignant pheochromocytomas and paragangliomas. Oncologist 18: 391-407, 2013.

50. de Wailly P, Oragano L, Radé F, Beaulieu A, Arnault V, Levillain P and Kraimps JL: Malignant pheochromocytoma: New malignancy criteria. Langenbecks Arch Surg 397: 239-246, 2012.

51. Aporowicz M, Czopnik P, Kubicka E, Piotrowska A, Dziegiel P, Bolanowski M and Domoslawski P: Minichromosome maintenance proteins MCM-3, MCM-5, MCM-7, and Ki-67 as proliferative markers in adrenocortical tumors. Anticancer Res 39: 1151-1159, 2019. 
52. Saiegh L, Sheikh-Ahmad M, Shechner C, Reut M, Darawsha Y, Zolotov S, Shefer H, Bejar I and Bejar J: Metallothionein protein and minichromosome maintenance protein-2 expression in adrenocortical tumors. Ann Endocrinol (Paris) 80: 324-328, 2019.

53. Romero Arenas MA, Whitsett TG, Aronova A, Henderson SA, LoBello J, Habra MA, Grubbs EG, Lee JE, Sircar K, Zarnegar R, et al: Protein expression of PTTG1 as a diagnostic biomarker in adrenocortical carcinoma. Ann Surg Oncol 25: 801-807, 2018.

54. Hirano Y, Nobata S, Takahashi H, Kageyama S, Sudoko H, Ushiyama T, Suzuki K and Fujita K: Histologically benign but telomerase positive adrenal pheochromocytoma. Int J Urol 9: 697-699, 2002

55. Kołomecki K, Stepień H and Narebski JM: Vascular endothelial growth factor and basic fibroblast growth factor evaluation in blood serum of patients with hormonally active and inactive adrenal gland tumours. Cytobios 101: 55-64, 2000.

56. Li L, Lei Q, Zhang S, Kong L and Qin B: Screening and identification of key biomarkers in hepatocellular carcinoma: Evidence from bioinformatic analysis. Oncol Rep 38: 2607-2618, 2017.

57. Panvichian R, Tantiwetrueangdet A, Angkathunyakul N and Leelaudomlipi S: TOP2A amplification and overexpression in hepatocellular carcinoma tissues. Biomed Res Int 2015: 381602 , 2015.

58. Wong N, Yeo W, Wong WL, Wong NL, Chan KY, Mo FK, Koh J, Chan SL, Chan AT, Lai PB, et al: TOP2A overexpression in hepatocellular carcinoma correlates with early age onset, shorter patients survival and chemoresistance. Int J Cancer 124: 644-652, 2009.
59. Guo J, Gu Y, Ma X, Zhang L, Li H, Yan Z, Han Y, Xie L and Guo X: Identification of hub genes and pathways in adrenocortical carcinoma by integrated bioinformatic analysis. J Cell Mol Med 24: 4428-4438, 2020.

60. Button KS, Ioannidis JP, Mokrysz C, Nosek BA, Flint J, Robinson ES and Munafò MR: Power failure: Why small sample size undermines the reliability of neuroscience. Nat Rev Neurosci 14: 365-376, 2013

61. Celestino R, Nome T, Pestana A, Hoff AM, Gonçalves AP, Pereira L, Cavadas B, Eloy C, Bjøro T, Sobrinho-Simões M, et al: CRABP1, C1QL1 and LCN2 are biomarkers of differentiated thyroid carcinoma, and predict extrathyroidal extension. BMC Cancer 18: 68, 2018.

62. Pinato DJ, Black JR, Trousil S, Dina RE, Trivedi P, Mauri FA and Sharma R: Programmed cell death ligands expression in phaeochromocytomas and paragangliomas: Relationship with the hypoxic response, immune evasion and malignant behavior. Oncoimmunology 6: e1358332, 2017.

63. Zhang L, Luo B, Dang YW, He RQ, Peng ZG, Chen G and Feng ZB: Clinical significance of microRNA-196b-5p in hepatocellular carcinoma and its potential molecular mechanism. J Cancer 10: 5355-5370, 2019.

This work is licensed under a Creative Commons Attribution-NonCommercial-NoDerivatives 4.0 International (CC BY-NC-ND 4.0) License. 